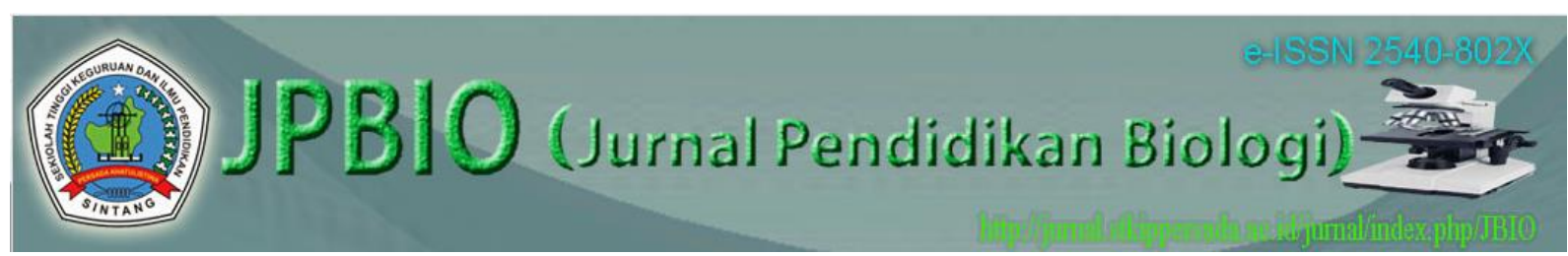

JPBIO (Jurnal Pendidikan Biologi)

Vol. 2 No. 1 April 2017 | $32-40$

ISSN 2540-802x (Online)

DOI: http://dx.doi.org/10.31932/ JPBIO (Jurnal Pendidikan Biologi)

http://jurnal.stkippersada.ac.id/jurnal/index.php/JBIO

\title{
EFEKTIVITAS MODEL PEMBELAJARAN CONCEPT SENTENCE TERHADAP HASIL BELAJAR KOGNITIFSISWA PADA MATERI ALAT INDRA MANUSIA KELAS IX SEKOLAH MENENGAH PERTAMA NEGERI 1 KAYAN HILIR TAHUN PELAJARAN 2017/2018
}

\author{
Natalia Wit ${ }^{1}$, Florentina Rahayu Esti Wahyuni ${ }^{2 *}$, Markus lyus Supiandi ${ }^{3}$ \\ ${ }^{1}$ Mahasiswa Program Studi Pendidikan Biologi, STKIP Persada Khatulistiwa Sintang \\ ${ }^{2,3}$ Dosen Program Studi Pendidikan Biologi, STKIP Persada Khatulistiwa Sintang \\ E-mail: nataliawit94@gmail.com; esti.pandi@ymail.com* \\ msupiandi@gmail.com
}

Diterima: 27 Februari 2017

Direvisi: 15 Maret 2017

Disetujui: 29 Maret 2017

\begin{abstract}
ABSTRAK
Penelitian ini dilatar belakangi oleh aktivitas siswa dalam proses pembelajaran dan hasil belajar kognitif siswa masih kurang. Tujuan dalam penelitian ini adalah untuk mengetahui pengaruh model pembelajaran concept sentence terhadap hasil belajar kognitif siswa pada materi alat indra manusia di kelas IX Sekolah Menegah Pertama Negeri 1 Kayan Hilir. Metode yang digunakan adalah kuantitatif, dengan bentuk eksperimen dan menggunakan rancangan quasy experiment dan desain penelitian nonequivalent control group design. Teknik pengambilan sampel purposive sampling. Teknik pengumpulan data menggunakan teknik observasi langsung, teknik pengukuran dan teknik komunikasi tidak langsung. Alat pengumpulan data yang digunakan berupa lembar observasi, soal tes dan lembar kausioner (angket). Teknik analisis data menggunakan uji prasyarat yaitu uji normalitas data, homegenitas data dan uji hipotesis, pada uji hipotesis menggunakan uji parametrik. Diperoleh rata-rata pre-test eksperimen 40,88 (rendah) dan kontrol 43,18 (rendah), rata-rata post-test eksperimen 75 (baik) dan kontrol 69,84 (rendah). Hasil analisis data observasi guru persentase rata-rata $100 \%$ berkriteria baik, sedangkan data observasi siswa persentase rata-rata $90,1 \%$ berkriteria baik. Teknik pengolahan data menggunakan uji normalitas data, diperoleh analisis data berdistribusi normal. Indeks Gains eksperimen 0,57 kategori sedang dan kontrol 0,46 kategori sedang. Hasil dari uji hipotesis data pretest diketahui bahwa nilai $Z_{\text {hitung }}$ adalah $-9,58$ sedangkan nilai $Z_{\text {tabel }}$ pada $\propto=5 \%$ adalah 1,96 . Hal ini berarti nilai $Z_{\text {hitung }}<$ $Z_{\text {tabel }}(-9,58<1,96)$ maka $H_{0}$ diterima. Sedangkan pada hasil uji hipotesis diperoleh pada data posttest diketahui bahwa nilai $Z_{\text {hitung }}$ adalah 19,84 sedangkan nilai $Z_{\text {tabel }}$ pada $\propto=5 \%$ adalah 1,96. Hal ini berarti nilai $Z_{\text {hitung }}>Z_{\text {tabel }}(19,84>1,96)$ maka $H_{1}$ diterima. Disimpulkan bahwa terdapat perbedaan yang signifikan hasil belajar kognitif siswa antara kelas eksperimen dan kontrol di kelas IX Sekolah Menengah Pertama Negeri 1 Kayan hilir pada materi alat indra manusia. Hasil angket respon siswa dengan rata-rata $87,1 \%$ (sangat kuat).
\end{abstract}

Kata kunci: concept sentence, hasil belajar kognitif siswa, alat indra manusia 


\section{ABSTRACT}

This research is based on student activity in learning process, building concept, analyzing material and cognitive learning result of students is still lacking. The purpose of this research is to know the effect of conceptual learning model to the students' cognitive learning outcomes on the material of the human senses in class IX First State School 1 Kayan Hilir. The method used is quantitative, with experimental form and using the design of quasy experiment and research design nonequivalent control group design. Sampling technique purposive sampling. Data collection techniques use direct observation techniques, measurement techniques and indirect communication techniques. Data collection tools used in the form of observation sheets, test questions and sheets of questionnaires (questionnaires). Data analysis technique using prerequisite test is data normality test, homegensity data and hypothesis test, on hypothesis test using parametric test. Obtain a mean of experimental pre-test 40,88 (low) and control 43,18 (low), average experimental post-test 75 (good) and control 69,84 (low). The result of data observation teacher percentage average $100 \%$ good criteria, while student observation data percentage average $90,1 \%$ good criteria. Data processing technique using data normality test, obtained by normal distribution data analysis. The experimental Gains index was 0.57 medium category and the control was 0.46 medium category. Result of hypothesis test of pretest data known that value of Zhitung is $-9,58$ while value of Ztabel at $\alpha=5 \%$ is 1,96. This means the value of Zhitung $<$ Ztabel $(-9.58<1.96)$ then $\mathrm{HO}$ is accepted. While the hypothesis test results obtained on posttest data note that the value of Zhitung is 19.84 while the value of Ztable at $\alpha=5 \%$ is 1.96. This means the value of Zhitung $>$ Ztable (19.84> 1.96) then $\mathrm{H} 1$ is accepted. It was concluded that there was a significant difference of students' cognitive learning outcomes between the experimental and control classes in IX Junior High School class 1 Kayan downstream

\section{Keywords: Concept Sentence, Student's Cognitive Learning Outcomes, Indra Eye Tools}

\section{PENDAHULUAN}

Dalam Undang-undang No.20 Tahun 2003 (Sugiyono, 2013: 42), tentang Sistem Pendidikan Nasional, "Pendidikan merupakan usaha sadar dan terencana untuk mewujudkan suasana belajar dan proses pembelajaran agar siswa secara aktif mengembangkan potensi dirinya untuk memiliki kekuatan spiritual, pengendalian dirinya, kepribadiannya dan kecerdasan serta keterampilan yang diperlukan oleh dirinya, masyarakat, bangsa dan negara". Menurut Widodo (2015: 300-301), "Pendidikan merupakan sebuah sarana untuk membangun martabat dan peradaban manusia sebagai seorang individu yang juga merupakan bagian dari suatu komunitas. Biologi sebagai salah satu cabang ilmu pengetahuan alam memfokuskan pembahasan pada masalah-masalah biologi di alam sekitar melalui proses dan sikap ilmiahsalah satu contohnya pada pokok bahasan alat indra manusia. Alat indra adalah alat-alat tubuh yang berfungsi mengetahui keadaan luar. Alat indra manusia sering disebut panca indra, karena terdiri dari lima indra yaitu indra penglihat, indra pendengar, indra pembau/pencium, indra pengecapdan indra peraba.

Berdasarkan hasil praobservasi yang dilakukan pada tanggal 24 April 2017 di Sekolah Menengah Pertama Negeri 1 Kayan Hilir ditemukan bahwa pada pembelajaran IPA masih ada siswa yang kurang mampu menguasai materi pembelajaran yang berkaitan pokok bahasan alat indra manusia, hal ini terlihat dengan dari rendahnya hasil belajar siswa yang tidak mencapai Kriteria Ketuntasan Minimal (KKM) yang ditetapkan oleh Sekolah Menengah Pertama Negeri 1 Kayan Hilir untuk mata pelajaran IPA yaitu 72. Berdasarkan nilai Ulangan Umum Semester Ganjil yang diperoleh siswa terdapat 55\% siswa mendapat nilai tidak tuntas. Menurut guru bidang studi IPA kelas IX Sekolah Menegah Pertama Negeri 1 Kayan Hilir hal ini dikarenakan dalam proses pembelajarannya, pembelajaran masih didominasi oleh guru sehingga siswa hanya bertindak sebagai penonton dan berpura-pura mengerti atau hanya diam saja ketika tidak mengerti materi yang sedang dipelajari serta ada pula beberapa siswa yang kurang percaya diri untuk menyampaikan pendapatnya. 
Adapun solusi yang diberikan oleh penulis agar pembelajaran IPA dapat dikemas sedemikian rupa, sehingga membuat siswa semangat dalam belajar dan menyukai pelajaran IPA. Salah satunya adalah menggunakan model Concept Sentence. Pembelajaran Concept Sentence merupakan pembelajaran yang lebih mengarah pada interaksi antara guru dengan siswa dan siswa dengan siswa. Menurut Huda (2013: 316) "Penggunaan model pembelajaran Metode Concept Sentence merupakan metode pembelajaran yang diawali dengan menyampaikan kompetensi, sajian materi, membentuk kelompok heterogen, guru menyiapkan kata kunci, sesuai materi bahan ajar, dan tiap kelompok membuat kalimat berdasarkan kata kunci. Prosedur selanjutnya dalam pembelajaran ini adalah mempresentasikan hasil belajar secara bergantian di depan kelas. Dalam Pembelajaran Concept Sentence mengkondisikan agar siswa terlibat aktif dalam proses belajar yaitu dengan menumbuhkan semangat belajar siswa.

\section{METODE PENELITIAN}

Pendekatan penelitian yang digunakan dalam penelitian ini adalah pendekatan kuantitatif. Metode penelitian yang digunakan dalam penelitian ini adalah penelitian Eksperimen. Dengan bentuk penelitian Quasi Experimental Design. Rancangan penelitian yaitu Nonequivalent Control Group Design.

Populasi dalam penelitian ini adalah seluruh kelas IX SMP Negeri 1 Kayan Hilir. Adapun sampel yg hendak diteliti yaitu kelas IX A sebagai kelas kontrol dan kelas IX B sebagai kelas eksperimen yang berjumlah 67 . Pengambilan sampel dilakukan dengan teknik purposive sampling.

Teknik pengumpulan data menggunakan teknik observasi langsung, teknik pengukuran dan teknik komunikasi tak langsung. Alat pengumpulan data adalah lembar observasi, soal tes dan angket

Teknik analisis data untuk hasil observasi dan hasil angket menggunakan rumus persentase. Selanjutnya untuk hasil tes siswa menggunakan uji prasyarat data penelitian melaluiuji homogenitas dan uji normalitas. Sedangkan uji hipotesis yang digunakan yaitu statistik parametrik, dengan menggunakan uji Z. Tes hasil belajar digunakan dengan menentukan N-Gain.

\section{HASIL PENELITIAN}

\section{Hasil Observasi}

\section{a. Observasi Guru dan Siswa Kelas Eksperimen}

Berdasarkan analisis observasi guru dan siswa pada pertemuan pertama dan kedua dikelas eksperimen, didapat rata-rata persentase pelaksanaan 100\% dan 90,1 dengan kriteria baik.

\section{b. Observasi Guru dan Siswa Kelas Kontrol}

Berdasarkan hasil observasi guru dan siswa pada pertemuan pertama dan kedua di kelas kontrolrata-ratanya $100 \%$ dan 88,37 dengan demikian hasil pengamatan berada pada rentang $81 \%-100 \%$ yang berkriteria baik

\section{c. Observasi Guru dan Siswa Kelas Eksperimen}

Hasil analisis lembar observasi guru dan siswa pada pertemuan pertama dan kedua diperoleh nilai persentase rata-rata sebesar $87,66 \%$ dan $82,26 \%$ yang berkategori baik.

\section{d. Observasi Guru dan Siswa Kelas Kontrol}

Dari hasil analisis lembar observasi guru dan siswa di kelas kontrol diperoleh persentase rata-rata sebesar $76,00 \%$ dan $79,00 \%$ dengan kategori baik.

\section{Hasil Belajar}

Hasil analisis data pretest dan posttest kelas eksperimen dan kelas kontrol dapat dilihat pada Tabel 1.

Tabel 1. Hasil Analisis Pretestdan Posttest Kelas Eksperimen dan Kelas Kontrol 


\begin{tabular}{lcccc}
\hline \multirow{2}{*}{ Jensi Data } & \multicolumn{2}{c}{ Kelas Eksperimen } & \multicolumn{2}{c}{ Kelas Kontrol } \\
\cline { 2 - 5 } & Pretest & Posttest & Pretest & Posttest \\
\hline Nilai Terendah & 30 & 60 & 30 & 60 \\
Nilai Tertinggi & 65 & 95 & 65 & 85 \\
Rata-rata & 40,88 & 75 & 43,18 & 69,84 \\
\hline
\end{tabular}

Hasil analisis data pretest dan posttest dari setiap tingkatan kognitif pada kelas eksperimen dan kelas kontrol dapat dilihat pada Tabel 2.

Tabel 2.Tabulasi Analisis Hasil Tes Siswa Tiap Tingkatan Kognitif

\begin{tabular}{cccccc}
\hline \multirow{2}{*}{ No } & $\begin{array}{c}\text { Tingkatan } \\
\text { Kognitif }\end{array}$ & \multicolumn{2}{c}{ Kelas Eksperimen } & \multicolumn{2}{c}{ Kelas Kontrol } \\
& Pretest & Posttest & Pretest & Posttest \\
\hline 1 & $\mathrm{C}_{1}$ & $71 \%$ & $98,8 \%$ & $76 \%$ & $86 \%$ \\
2 & $\mathrm{C}_{2}$ & $83 \%$ & $97 \%$ & $82 \%$ & $94 \%$ \\
3 & $\mathrm{C}_{3}$ & $81 \%$ & $95 \%$ & $81 \%$ & $96 \%$ \\
4 & $\mathrm{C}_{4}$ & $61 \%$ & $75 \%$ & $60 \%$ & $74 \%$ \\
\hline
\end{tabular}

Untuk membuktikan data secara statistik maka data pre-test kelas eksperimen dan kelas kontrolakan diuji dengan Uji normalitas data pre-test kelas eksperimen dan kelas kontrolmenggunakan uji $X^{2}$.Dengan jumlah sampel masing-masing 34 siswa diperoleh $\mathrm{X}^{2}{ }_{\text {hitung }}=6,69<7,815$, pretest kelas IX A sebagai kelas kontrol 6,03 $<7,815$, posttest kelas IX B sebagai kelas eksperimen $7,78<7,815$, posttest kelas IX A sebagai kelas kontrol 4,9< 7,815 maka dapat dinyatakan bahwa sebaran data kelas IX B dan IX A dalam penelitian ini berdistribusi normal. Untuk lebih jelasnya, hasil uji normalitas dapat dilihat pada Tabel 3.

Tabel 3. Hasil Uji Normalitas Data

\begin{tabular}{llllll}
\hline Data yang dikaji & $\mathbf{N}$ & $\mathbf{X}^{2}{ }_{\text {hitung }}$ & $\mathbf{X}^{\mathbf{2}}$ table & $\mathbf{A}$ & Ket. \\
\hline Pretest Eksperimen & 34 & 6,69 & 8,15 & 0,05 & Normal \\
\hline Pretest Kontrol & 33 & 603 & 8,15 & 0,05 & Normal \\
\hline Posttest Eksperimen & 34 & 7,78 & 8,15 & 0,05 & Normal \\
\hline Posttest Kontrol & 33 & 4,9 & 8,15 & 0,05 & Normal \\
\hline
\end{tabular}

Hasil perhitungan menunjukkan bahwa $F_{\text {hitung }}<F_{\text {tabel, }}$ yaitu pretest pada kelas eksperimen dan kelas kontrol sebesar1,38 < 1,81. "Homogen". Sedangkan untuk hasil perhitungan uji homogenitas posttest kelas eksperimen dan kontrol menunjukkan bahwa $F_{\text {hitung }}<F_{\text {tabel, }}$ yaitu postest kelas eksperimen dan kelas kontrol sebesar 1,04< 1,814"Homogen". Untuk lebih jelasnya dapat dilihat pada Tabel 4.

Tabel 4. Hasil Uji Homogenitas

\begin{tabular}{|c|c|c|c|c|c|}
\hline No & Data Yang Diuji & $S^{2}$ & $F_{\text {hitung }}$ & $F_{\text {tabel }}$ & Keterangan \\
\hline 1 & $\begin{array}{l}\text { Pretest } \\
\text { Eksperimen }\end{array}$ & 55,25 & 1,38 & 1,81 & Homogen \\
\hline 2 & Pretest Kontrol & 76,27 & & & \\
\hline 3 & $\begin{array}{l}\text { Posttest } \\
\text { Eksperimen }\end{array}$ & 74,24 & 1,04 & 1,814 & Homogen \\
\hline 4 & Posttest Kontrol & 71,07 & & & \\
\hline
\end{tabular}

Berdasarkanhasil perhitungan diketahui bahwa nilai $Z_{\text {hitung }}$ adalah $-9,58$ sedangkan nilai $t_{\text {tabel }}$ adalah 1,96 maka Ho diterima, artinya tidak terdapat perbedaan yang signifikan hasil belajar kognitif siswa antara siswa kelas eksperimen dan siswa kelas kontrol sebelum pembelajaran dengan menggunakan pembelajaran konvensional.Untuk lebih jelasnya 
dapat dilihat pada Tabel 5.

Tabel 5. Uji Hipotesis pretest kelas eksperimen dan kelas kontrol

\begin{tabular}{cccccc}
\hline Kelas & $\mathbf{N}$ & $\begin{array}{c}\text { Rerata } \\
\text { Pretest }\end{array}$ & $\mathbf{Z}_{\text {hitung }}$ & $\mathbf{t}_{\text {tabel }}$ & Keterangan \\
\hline $\begin{array}{c}\text { IX }{ }^{\mathrm{A}} \text { (Kelas } \\
\text { kontrol) }\end{array}$ & 33 & 40,48 & & & \\
$\begin{array}{c}\text { IX }(\text { Kelas } \\
\text { eksperimenl) }\end{array}$ & 34 & 43,18 & $-9,58$ & 1,96 & $\begin{array}{c}H_{a} \text { ditolak dan } \\
H_{0} \text { diterima }\end{array}$ \\
\hline
\end{tabular}

Berdasarkan hasil perhitungan diketahui bahwa nilai $Z_{\text {hitung }}$ adalah 19,84 sedangkan nilai $Z_{\text {tabel }}$ adalah 1,96 maka Ha diterima artinya terdapat perbedaan yang signifikan hasil belajar kognitif siswa di kelas eksperimenyang diberi perlakuan menggunakan model pembelajaran Concept Sentence dengan kelas kontrol yang diberi perlakuan menggunakan model pembelajaran konvensional pada materi alat indra manusia kelas IX Sekolah Pertama Negeri 1 Kayan Hilir Tahun Pelajaran 2017/2018. Untuk lebih jelasnya dapat dilihat pada Tabel 6.

Tabel 6. Hasil Uji Hipotesis posttest Kelas Eksperimen dan Kontrol

\begin{tabular}{|c|c|c|c|c|c|}
\hline Kelas & $\mathbf{N}$ & Rerata Posttest & $Z_{\text {hitung }}$ & $\mathbf{Z}_{\text {tabel }}$ & Keterangan \\
\hline $\mathrm{IX}^{\mathrm{A}}$ (Kelas kontrol) & 33 & 69,84 & & & \\
\hline IXB (Kelaseksperimenl) & 34 & 75 & 19,84 & 1,96 & dan $\mathrm{H}_{0}$ ditolak \\
\hline
\end{tabular}

Dari data hasil posttest siswa kelas kontrol dan kelas eksperimen diperoleh skor ratarata kelas kontrol sebesar 69,84 dan skor rata - rata kelas eksperimen sebesar 75 standar deviasi untuk kelompok kontrol sebesar 8,43 dengan demikian:

$\mathrm{ES}=\frac{75-69,84}{8,43}=0,61$

Karena harga effect size (ES) sebesar 0,61 dan termasuk dalam kriteria tinggi maka dapat dinyatakan bahwa pembelajaran dengan menggunakan model pembelajaran Concept Sentence memiliki efektivitas tinggi terhadap hasil belajar kognitif siswa. Analisis Indeks Gain Hake pada penelitian ini bertujuan untuk mengukur kualitas peningkatan hasil belajar kognitif siswa kelas eksperimen dan kelas kontrol. Data yang digunakan dalam perhitungan Indeks Gain Hake adalah nilai pretest dan posttest kelas eksperimen dan kelas kontrol. Rekapitulasi hasil analisis indeks gain hake.

a) Peningkatan Pengetahuan Hasil Belajar Kognitif Siswa Kelas Eksperimen

$$
\text { IndeksGainHake }=\frac{\text { Rerataposttest }- \text { Reratapretest }}{\text { NilaiMaksimal }- \text { Reratapretest }}
$$

$N$ Gain $=\frac{75-40,88}{100-40,88}=\frac{34,12}{59,12}=0,57$

Jadi $N$ - Gain pada kelas eksperimen adalah 0,57 kategori sedang.

b) Peningkatan Pengetahuan Hasil Belajar Kognitif Siswa Kelas Kontrol

$$
\text { IndeksGainHake }=\frac{\text { Rerataposttest }- \text { Reratapretest }}{\text { NilaiMaksimal }- \text { Reratapretest }}
$$

$N$ Gain $=\frac{69,84-43,18}{100-43,18}=\frac{26,66}{56,82}=0,46$.

Jadi $N$ - Gain pada kelas eksperimen adalah 0,46 kategori sedang.

\section{Respon Siswa}


Untuk mengetahui respon siswa terhadap diterapkannya model pembelajaran Concept Sentence dapat dilihat pada Tabel 7.

Tabel 7 Analisi Angket Respon Siswa

\begin{tabular}{cccc}
\hline $\begin{array}{c}\text { Nomor } \\
\text { Angket }\end{array}$ & $\begin{array}{c}\text { Rata-Rata } \\
\text { Presentase }\end{array}$ & No Angket & Rata-Rata Presentase \\
\hline 1 & $92,00 \%$ & 11 & $84,00 \%$ \\
2 & $90,28 \%$ & 12 & $85,14 \%$ \\
3 & $82,82 \%$ & 13 & $88,00 \%$ \\
4 & $82,82 \%$ & 14 & $86,85 \%$ \\
5 & $88,00 \%$ & 15 & $88,57 \%$ \\
6 & $88,57 \%$ & 16 & $80,00 \%$ \\
7 & $83,42 \%$ & 17 & $91,42 \%$ \\
8 & $85,71 \%$ & 18 & $87,71 \%$ \\
9 & $90,83 \%$ & 19 & $86,85 \%$ \\
10 & $90,85 \%$ & 20 & $86,28 \%$ \\
\hline & Jumlah & & $\mathbf{1 7 4 1 , 0 4}$ \\
\hline
\end{tabular}

Berdasarkan hasil rekapitulasi persentase jawaban, diperoleh rata-rata persentase sebesar $87,1 \%$ dan dikategorikan sangat kuat. Dari hasil angket tersebut menunjukan bahwa siswa merespon dengan sangat baik pembelajaran menggunakan model Concept Sentence. Adapun upaya yang dilakukan adalah menguasai kelas supaya siswa lebih memperhatiakn materi yang disampaikan dan membuat suasana kelas menjadi lebih menarik sehingga siswa tidak merasa bosan saat pembelajaran berlangsung.

\section{PEMBAHASAN}

\section{Hasil Observasi}

\section{a. Observasi Guru dan Siswa Kelas Eksperimen}

Dari hasil analisis lembar observasi guru di kelas eksperimen dengan menggunakan model pembelajaran Concept Sentence diperoleh persentase rata-rata sebesar $100 \%$ yang berkategori baik. sedangkandari hasil analisi lembar observasi siswa di kelas eksperimen dengan menggunakan model pembelajaran Concept Sentence diperoleh persentase ratarata sebesar $90,1 \%$ dengan kategori baik. Artinya dari pertemuan pertama dan kedua siswa telah mengikuti proses pembelajaran mulai dari pendahuluan sampai penutupan pembelajaran dengan baik.Penelitian ini sejalan dengan yang dilakukan Feni Romaningsih, (2014)bahwa pembelajaran dengan menggunakan model pembelajaran concept sentence berpengaruh terhadap hasil belajar IPA dibandingkan dengan model pembelajaran konvensional pada siswa kelas IV Semester Ganjil Tahun Pelajaran 2013/2014 di Sekolah Dasar Negeri 7 Karang Rayung Kabupaten Grobogan.

\section{b. Observasi Guru dan Siswa Kelas Kontrol}

Dari hasil analisis lembar observasi guru di kelas kontrol diperoleh persentase rata-rata sebesar $100 \%$ yang berkategori baik. sedangkan dari hasil analisi lembar observasi siswa di kelas kontrol diperoleh persentase rata-rata sebesar $88,37 \%$ dengan kategori baik. Artinya dari pertemuan pertama dan kedua siswa telah mengikuti proses pembelajaran mulai dari pendahuluan sampai penutupan pembelajaran dengan baik dengan menggunakan pembelajaran konvensional..Penelitian yang dilakukan Alan Mutahir, Asep Darodjat (2011) dengan judul "Pengaruh Model Pembelajaran Cooperative Tipe Concept Sentence Terhadap Hasil Belajar Matematika Siswa", Menyimpulkan bahwa kemampuan hasil belajar siswa meningkat setelah diterapkan model pembelajaran Cooperative Tipe Concept Sentence dengan ratarata nilai pretest sebesar 58 menjadi nilai postest sebesar 82,91 dengan peningkatan nilai 
rerata sebesar 27,91 dan rata-rata nilai pretest kelas kontrol nilai sebesar 60,00 dengan perbedaan nilai sebesar 5,4 .

\section{Hasil Belajar Siswa}

a. Hasil Belajar Kognitif Siswa Sebelum (Pre-test) dan Sesudah (Post-test) Di Kelas Eksperimen

Hasil belajar kognitif siswa pada pre-testdan post-test kelas eksperimen ada perubahan, terlihat dari nilai rata-rata pre-testsebesar 40,88 sedangkan nilai rata-rata posttest 75 maka diperoleh selisih nilai sebesar 34,12. Selisih nilai sebesar 34,12 merupakan selisih yang cukup besar. Artinya pada keadaan awal nilai yang diperoleh merupakan hasil dari metode konvesional tampa pembelajaran model pembelajaran Concept Sentence Hal ini Sejalan dengan pendapat yang dilakukan Kornelia (2015) menyatakan bahwa rata-rata nilai posttest kelas eksperimen 79,1 poin lebih tinggi dari nilai pretest nya. Persentase ketuntasan siswa pada saat pretest adalah $0 \%$, sedangkan persentase ketuntasan siswa pada saat posttest adalah 95,56\%.

\section{b. Hasil Belajar Kognitif Siswa Sebelum (Pre-test) dan Sesudah (Post-test) Di Kelas Kontrol}

Hasil belajar kognitif siswa pada pre-testdan post-test kelas kontrol tidak mengalami perubahan yang berarti, terlihat dari nilai rata-rata pre-test sebesar 43,18 sedangkan nilai rata-rata post-test 69,84 . Artinya pada keadaan awal nilai yang diperoleh merupakan hasil dari pembelajaran konvensional tanpa menggunakan media pembelajaran, kemudian tidak mengalami perubahan yang berarti setelah diberikan pembelajaran ulang degan model pembelajaran konvensional.

\section{c. Perbedaan yang Signifikan Hasil Belajar Kognitif Siswa Sebelum (Pre-test) dan Sesudah (Post-test) di Kelas Eksperimen dan Kelas Kontrol}

Data yang diuji berupa data post-test kelas eksperimen dan kelas kontrol dengan variansi 75 dan 69,84 diperoleh $Z_{\text {tabel }}=19,84$ pada tingkat signifikansi 0,05 didapat $Z_{\text {tabel }}=1,96$ dan $Z_{\text {hitung }}>Z_{\text {tabel }}$ atau $(19,84>1,96)$ atau $\mathrm{H}_{0}$ di tolak maka $\mathrm{H}_{a}$ di terima artinya terdapat perbedaan yang signifikant pada nilai post-test pada kelas eksperimen maupun kelas kontrol.

\section{d. Efektivitas Model Concept Sentence Terhadap Hasil Belajar Kognitif Siswa}

Efektivitas dari model pembelajaran yang digunakan dalam penelitian ini berdasarkan kriteria yang diproleh dinyatakan "Sedang", Karena harga effect size (ES) sebesar 0,61. Hal ini sejalan dengan penelitian yang dilakukan Eka Mayasari (2014) dengan judul Efektivitas Model Pembelajaran Concept Sentence Terhadap Hasil Belajar siswa. Karangan Narasi Siswa menyatakan bahwa Setelah dihitung Effect Size untuk hasil belajar siswa maka diperoleh hasil 2,189 dan termasuk kriteria sedang.

Sedangkan Data yang digunakan dalam perhitungan Indeks Gain Hake adalah nilai pretest dan posttest kelas eksperimen dan kelas kontrol memperoleh nilai 0,57 berkriteria sedang. Sementara hasil belajar kognitif siswa pada kelas kontrol 0,46 berkriteria sedang. Penelitian ini sejalan dengan Penelitian yang dilakukan Aziz Bahar Kholid (2015) menyatakan bahwa hasil analisis indeks gain hake berkriteria sedang dengan skor nilai pada kelas eksperimen 0,63 berkriteria sedang dan kelas kontrol 0,30 berkriteria sedang.

\section{Respon Siswa}

Penelitian ini juga didukung oleh angket untuk mengetahui tanggapan siswa terhadap penerapan model pembelajaran Concept Sentence. Berdasarkan hasil presentase rekapitulasi jawaban dari tanggapan 34 responden yang diberi angket, dapat diketahui bahwa perolehan total rata-rata jawaban sebesar $1741,04 \%$ dengan rata-rata persentase 
$87,1 \%$, hal ini dapat diketahui bahwa respon siswa yang menjawab "Ya" dengan rata-rata persentase sebesar $87,1 \%$ dan respon siswa yang menjawab "Tidak" dengan rata-rata persentase 12,9\% dan apabila dikonversikan masuk kriteria sangat kuat. Yuliana (2014) dengan judul "Efektivitas Metode Pembelajaran Concept Sentence Terhadap Hasil Belajar Siswa pada Materi Fungsi Sistem Jaringan Tumbuhan di Kelas VIII SMP" yang menyatakan bahwa:

Berdasarkan hasil analisis data diperoleh persentase total $82 \%$ dengan kategori sangat kuat atau penggunaan model pembelajaran concept sentence mendapat respon sangat baik untuk membantu siswa dalam meningkatkan hasil belajar siswa.

\section{SIMPULAN}

Berdasarkan dari hasil penelitian yang telah dilaksanakan, dapat disimpulkan bahwa: (1) Proses pembelajaran guru dan siswadi kelas eksperimenmenggunakan model pembelajaran Concept Sentencepada materi alat indra berjalan dengan baik; (2) Proses pembelajaran guru dan siswa di kelas kontrol dengan diterapkan model pembelajaran konvensional pada materi alat indra manusia berjalan dengan baik; (3) Terdapat perbedaan hasil belajar kognitif siswa kelas eksperimen dan kontrol pada pengukuran awal (pretest) pada materi alat indra manusia di kelas IX Sekolah Menengah Pertama Negeri 1 Kayan Hilir. Hal ini terlihat dari hasil rata-rata Pretest kelas eksperimen sebesar 40,88 dengan kategori kurang, dan rata-rata kelas kontrol sebesar 43,18 dengan kategori kurang; (4) Terdapat perbedaan hasil belajar kognitif siswa kelas eksperimen dan kontrol pada pengukuran akhir (posttest) pada materi alat indra manusia di kelas IX Sekolah Menengah Pertama Negeri 1 Kayan Hilir. Hal ini terlihat dari hasil rata-rata posttest kelas eksperimen sebesar 75 dengan kategori baik dan rata-rata kelas kontrol sebesar 69,84 dengan kategori kurang; (5) Hasil pretest menunjukan bahwa nilai $Z_{\text {hitung }}(-9,58)<Z_{\text {tabel }}(1,96)$ maka $H_{1}$ diterima yang artinya tidak terdapat perbedaan yang signifikan hasil belajar kognitif siswa antara kelas eksperimen yang menggunakan model pembelajaran Concept Sentence dengan kelas kontrol yang menggunakan model pembelajaran konvensional pada materi alat indra manusia. Sedangkan hasil posttestmenunjukan bahwa nilai $Z_{\text {hitung }}(19,84)>Z_{\text {tabel }}(1,96)$ maka $\mathrm{Ha}$ diterima yang artinya terdapat perbedaan yang signifikan hasil belajar kognitif siswa antara kelas eksperimen yang menggunakan model pembelajaran Concept Sentence dengan kelas kontrol yang menggunakan model pembelajaran konvensional pada materi alat indra manusia; (6) Dari hasil harga effect size (ES) sebesar 0,61 dan termasuk dalam kriteria sedang dapat disimpulkan bahwa pembelajaran dengan menggunakan model pembelajaran Concept Sentence memiliki efektivitas sedang terhadap hasil belajar kognitif siswa; (7) Tanggapan siswa terhadap penerapan model pembelajaran Concept Sentence pada pokok bahasan alat indra manusia di kelas IX SMP Negeri 1 Kayan Hilir dengan kategori sangat kuat dengan perolehan rata-rata persentase sebesar $87,1 \%$

\section{REFERENSI}

Arikunto, S. (2010). Prosedur Penelitian Suatu Pendekatan Praktik. Jakarta: Rineka Cipta

Huda, M. (2013). Model-model Pengajaran dan Pembelajaran. Yogyakarta: Pustaka Pelajar.

Mutahir, A. dkk. 2011. Pengaruh Model Pembelajaran Cooperative Tipe Concept Sentence Terhadap Hasil Belajar Matematika Siswa. Jurnal Kalam Cendekia, 3(3.1). 297-302.

Romaningsih, F. (2014). Penerapan MetodeConcept Sentence Dapat Meningkatkan Keaktifan Belajar Bahasa Indonesia Kelas IV Sd Negeri 7 Karangrayung Kecamatan Karangrayunng Kabupaten Grobogan Tahun Pelajaran 2013/2014. Jurnal ibidandiah, 2, (11). 
Sudjana, N. (2009). Penilaian Hasil Proses Belajar Mengajar. Bandung: Remaja Rosdakarya.

Sugiyono. (2013). Metode Penelitian Pendidikan (Pendekatan Kuantitatif, Kualitatif,dan $R \& D)$. Bandung: Alfabeta.

Sugiyono. (2013). Statistika Untuk Penelitian. Bandung: Alfabeta

Wit. N. (2017). Efektivitas Model Pembelajaran Concept Sentence Terhadap Hasil Belajar KognitifSiswa Pada Materi Alat Indra Manusia Kelas IX Sekolah Menengah Pertama Negeri 1 Kayan Hilir Tahun Pelajaran 2017/2018. Skripsi tidak diterbitkan. Sintang: STKIP Persada Khatulistiwa Sintang. 